\title{
Incorrect, fake, and false. Journalists' perceived online source credibility and verification behavior
}

\author{
Maurice Vergeer* \\ *Radboud University Nijmegen, The Netherlands
}

Abstract

\begin{abstract}
This study focuses on the extent journalists verify information provided by online sources, and tests to what extent this verification behavior can be explained by journalists' perceived credibility of online information and other factors, such as journalism education of journalists, work and Internet experience, and work environment (broadcasting, newspapers, Internet). Although several studies have focused on perceived credibility of online information, none have tested its effect on actual verification behavior. This study will perform that test.

Using a sample from the membership database of the Dutch Association of Journalists, a web questionnaire was used to ask journalists about their opinions, behavior, and professional background characteristics. Regression analysis was used to test the hypotheses.

Analyses show that journalism education does not affect journalists' verification behavior, neither directly nor indirectly via perceived online source credibility. Perceiving online information as less credible does not lead to verifying online information more extensively. Journalism education only affects the extent journalists perceive online (semi-) governmental information as less credible.

The findings question the role of formal and informal professional socialization in training journalists to become professional journalists adhering to professional standards.
\end{abstract}

Keywords: journalism; professional socialization; perceived information credibility; verification behavior; Internet experience; news production

While the Internet provides journalists with many new advantages, such as ease of information retrieval, increased speed of publishing, and new ways to reach audiences, recent years has shown that using the Internet for information gathering is not too take lightly. The Web and social media seem quite "error-prone" (Porlezza \& RussMohl, 2012), or put more bluntly: unreliable, untrusted and outright fake. The US election campaign of 2016 showed several examples fake news websites and messages during the campaign battle between Donald Trump and Hillary Clinton (Kirby, 2016).

Fake news and incorrect information in general have been a matter for concern, even in the pre-Internet era. Davis' contribution (Davies, 2009) about churnalism rekindled journalists' and journalism scholars' focus on uncritical handling of information in the news production process. While the need for caution towards the quality is essential for information in general, there are several reasons why concerns about online information credibility are more pronounced. First, online information is digital and can be tampered with much more easily than printed information. It is freely available in massive amounts. Furthermore, the dissemination of online information is easier and quicker due to the lack of physical boundaries as well as the diffusion through social media such as Twitter and Facebook, explaining the larger reach of online information. Another reason for the large reach of news in the Internet era is that, opposed to the pre-Internet era where media professionals had a monopoly on producing and disseminating news, non-professionals gained access to easy-to-use publishing technology (i.e. websites, weblogs) and particularly social media to redistribute news to personal online networks (Larsson, 2016). Additionally, search engine architecture, such as Google's PageRank algorithm (Page, Brin, Motwani \& Winograd, 2001), produces search results based on the popularity of content. It assumes that content which is most linked to (e.g. indegree: the number of hyperlinks pointing to in this case, web pages) has greater authority. Google, being the most popular

Copyright (c) 2018 (Maurice Vergeer). Licensed under the Creative Commons Attribution-NonCommercial Generic (cc by-nc). Available at http://obs.obercom.pt. 
search engine in Europe and North America, creates a biased Web environment governed by popularity instead of trustworthiness. This is more problematic when most users of Google search-engine never see search results beyond Google's first page, as Tylor (2015) found for journalism students. In such a biased information environment journalists are expected to approach information more carefully by checking what information is credible enough to be used in news reports. Also, the production cycle of news has changed as well. The traditional 24-hour cycle of news production, particularly common in the printed newspaper industry, has become less relevant (Hermida, 2012). Many news organizations switched to the model of "online first": news is published directly onto the Web, and, if still relevant and less time sensitive, it will also be published in printed newspapers or TV broadcasts. New news platforms even do not publish offline (e.g. physical newspapers) anymore. Thus, journalists have less time to verify online information (cf. Chan, Lee \& Pan, 2006). This is furthermore aggravated because increased competition, cost-effectiveness, and efficiency on the work floor (Grabowicz, 2003; Haas, 2006; Lasica, 2003; Pavlik, 2001) has led to many lay-offs. Journalists now need to produce content with a smaller staff and smaller budgets. This leads to a situation where a smaller journalistic workforce needs to supply news as soon as possible to its audience, based on a supply on online information which is - in part - unreliable, untrustworthy, or even plain fake. This then raises the question how journalists determine what is trustworthy, correct and true, and thus suitable to use for news production?

In our study, we base our definition of information credibility on Yoon's definition (2005): "It is the degree to which information from an organization is accurate, fair, unbiased, and trustworthy" (2005, pp. 182). Reporting accurate information is of the utmost importance for society and media companies. Inaccurate reports can have severe repercussions for people involved in the reported events, but also for readers and viewers who base their future decisions on information. For media companies, publishing inaccurate information can undermine people's trust in news media as a product and as a brand for providing accurate news and can have economic consequences due to cancellation of subscriptions or less viewers on their websites, reducing their financial turnover.

Our study thus focuses on perceived credibility of online information and verifying online information. There are several studies on people's and journalists' perceived credibility of online information (Cassidy, 2007; Flanagin and Metzger, 2000; Johnson and Kaye, 2002, 2004, 2015; Porlezza \& Russ-Mohl, 2012; Reich, 2011). Our study contributes to this research field in a number of ways. Firstly, we will focus on the relation between these two concepts of information credibility and checking behavior, and embed the concepts in an explanatory model. Secondly, even though studies include the level of education as a control variable, the role of journalism education in explaining perceived credibility and verification behavior is ignored. Journalism education caters specifically to future journalists, who will deal professionally with online information. Not only for themselves, but also for the citizens they serve by providing news, based on (in part) online information. As such, journalism education, taught by peers, trains students in the practices, techniques and routines on how to produce news professionally. Because the news is produced for the general public, the quality of online information (or lack thereof) may have far-reaching consequences. Our study will fill this gap by testing the specific role of journalism education as additional to the contribution of secondary education explicitly. The research questions in our study are: (1) to what extent is perceived credibility of online information associated with verification behavior, (2) to what extent is professional socialization associated with journalists' behavior of verifying the accuracy of online information? Answering these questions may provide opportunities to improve the journalists' skills and critical perspectives to bring the best and most reliable news for citizens. 


\section{Explaining perceived credibility of online information and verification behavior}

We distinguish several domains that provide possible explanations for verification behavior and perceived credibility of sources and online information. These domains are professional socialization, perceptions of online information, and professional work environment.

Professional socialization: education and work experience

To become a professional journalist, people can take different educational paths. Most journalists have at least general education (e.g. secondary school, higher journalism education such as universities of applied sciences, and higher academic education such as universities). Others also enjoy specialized educational programs focusing on journalism: e.g. schools of journalism (in universities of applied sciences) educate students to become professional journalists and university master programs and post-academic programs which also focus on the academic study of journalism. Previous research (Deursen \& Dijk, 2015; Maksl, Craft, Ashley, \& Miller, 2016) has shown that higher levels of education is associated with more Internet skills and higher levels of media literacy, suggesting that education trains students to acquire a critical attitude towards information in general (cf. perceived credibility) and how to assess the quality of online information (i.e. skills for verify information accuracy). Therefore, we expect that journalism education has a positive effect on journalists' verification behavior, in the sense that the higher the level of education, the more journalists will check online information on its accuracy. Therefore, we hypothesize as follows:

Hypothesis 1: Journalists with a higher journalism education will check web information more often.

Although professionalization begins with education, it doesn't end there. Once students have completed journalism education, socialization continues when they enter the news organization surrounded by other more experienced journalists and editors. Journalists are continuously checked by their peers on the work floor in an informal manner, whether it is by complimenting each other on a job well performed and critiquing each other when they did not perform well. These evaluations of journalists' performance on the work floor are expected to socialize them consistent with requirements for professional journalism. This is particularly the case when journalists stay longer periods of time in a similar journalistic environment. This implies that work experience is an important indicator for informal socialization in the newsroom (Breed, 1955). Even in the era of social media, journalists connect strongly amongst each other creating tightly knit communities (Vergeer, 2015). Therefore, we expect that the longer a journalist works in journalism, the more he is affected by peer influence on how to perform as a professional journalist. Therefore, the hypothesis is as follows:

Hypothesis 2: The more work experience journalists have, the more extensively journalists will verify online information. 


\section{Perceived credibility as mediator}

An explanation of verification behavior merely based on journalism education and work experience is quite limited: a direct effect of journalism education on verification behavior then could be interpreted as performing a specific skill, having been taught in university or school of journalism. It ignores a possible internalization of a motive to verify online information. A motive to verify online information can be based in a belief that online information is inherently inaccurate. The question then arises to what extent journalism education and experience contribute to students' perception of online information credibility? According to Reich (2011) credibility of sources and information is a matter of practical skepticism. This means that the level of perceived credibility is directly related to journalists' actions of verifying or refuting source's assertions (2011, pp. 60): the less credible a source is perceived, the more cross-checking needs to be done. Perceiving online information as less credible and therefore verifying information more extensively indicates that journalists are more aware of inferior online information and verify information not merely as a journalistic routine but because of a motive based on a belief (cf. practical skepticism). Therefore, we will test whether journalism education plays important role in creating a perception of online information being less credible. And if so, whether this perception of less credibility subsequently leads to more verifying its credibility by checking it by using multiple sources? To test this indirect effect, we pose the following mediation hypothesis:

Hypothesis 3: The relation between professional education and online information verification is mediated by the perceived credibility of online information.

Cassidy's study on online news credibility (2007) suggests that journalists relying on the Internet to perform their job will perceive online news as being more credible. Similarly, his study shows that journalists who are a member of the newspaper's online staff also perceive online news as credible. Another study by Chan, Lee and Pan (2006) also indicates a positive relation between journalists' perceived credibility of mainstream news sites and the use of the Internet, although this relation was not present for commercial news sites. Research among regular users shows similar findings. Flanagin and Metzger (2000) show that experience using the Internet is correlated positively with perceived credibility and verification of reputable sites. Similarly, findings from Johnson and Kaye $(2000,2014)$ suggest that increased use of online information correlates with increased credibility. These findings suggest that journalists who spend more time on the Internet routinely also perceive online information as more credible. Furthermore, we expect that the more journalists perceive online information as credibility, they will check online information less often because they take the quality for granted. Therefore, the mediation hypothesis for time spent on the Internet is as follows:

Hypothesis 4: The more time journalists spent on the Internet, the less they will check online information, because they perceive online information as more credible.

\section{Journalistic tasks and work field}

It has been suggested that specific tasks performed within news organizations and working for specific publishing platform also affects journalists' verification behavior of online information. For instance, journalists that are particularly involved in traditional news production (e.g. writing journalism on offline world) are expected to be more critical of online information and therefore will verify online information more often. According to Singer 
(2004) newspaper and print journalists seem to be ambivalent "about the perceived effect of convergence on professional norms of credibility, accuracy and quality" (Singer, 2004, p. 842). These journalists are considered to be more traditional regarding their journalistic routines than those working for online media. Therefore, these journalists are expected to be more cautious using new technology and subsequently judge online information as less credible than journalists working for online media and audiovisual media (Cassidy, 2005; Deuze and Dimoudi, 2002; Ruggiero, 2004; Weaver, Beam, Brownlee, Voakes \& Wilhoit, 2007). Journalists working for online and audiovisual media routinely come in contact with online information, and therefore may not explicitly question the credibility of online information.

Hypothesis 5: Journalists working for newspapers or magazines will check online information more often, because they perceive online information as less credible than other journalists.

Performing specific tasks in journalism might also explain the level of perceived credibility and subsequent checking of information. This would specifically apply to journalists who report the news, but also members of the online staff (Cassidy, 2007). Reporters communicate the news to the audience and need to be certain that their information is accurate and therefore need to verify information more often. These reporters are the ones in the public eye and therefore perceived as responsible for publishing inaccurate information. Members of the online staff spend much time online to gather information. As such they should be experienced in knowing what reliable and unreliable sources are and therefore be able to avoid unreliable sources routinely. This then results in less need to check online information. The hypothesis are as follows:

Hypothesis 6a: Journalists who report the news verify online information more often, because they perceive online information as less credible than other journalists.

Hypothesis 6b: Journalists who are on the online staff verify online information less often, because they perceive online information as more credible than other journalists.

Performing thorough checks on information quality during news production takes time. This implies that having ample time available is necessary to provide high quality news to the audience. This suggests that the available weekly time budget journalists have is likely to affect the extent journalists can perform these checks, suggesting a positive association between the available time budget and the level of checking behavior. At the same time, Weischenberg, Malik and Scholl (2012) shows that freelancers (who have a smaller time budget), perform more investigating and information gathering than full-time employed journalists who spend more time on editing and managing. Given these diverging expectations, we pose the following hypothesis:

Hypothesis 7: Journalists' time budget is significantly associated (positively or negatively) with checking online information.

We will also take account of a few control variables. Regarding age, previous research has shown that younger people are early adopters of new technology. Younger people adopt the Internet as an information source more quickly, while older people are more apprehensive about using the Internet (Van Deursen and Van Dijk, 2011). The 
use of the Internet also involves the use of specific skills. Research has shown that the older people are less able to use the Internet because they lack the necessary skills (Hargittai and Hinnant, 2008). Therefore, it prevents older people (and also older journalists) to verify the credibility of online information. This suggests a direct effect of age on verification behavior due to lacking skills. This results in the following hypotheses:

Hypothesis 8: The older journalists are, the less they check online information.

Although we use journalism education as an important explanation for perceived credibility of and verification behavior of online information (see Hypothesis 1 and 3), we will also include secondary education as an explanation, in order to test whether journalism education and general education have distinguishable effects. We expect that the higher the general secondary education journalists have had, the more they are able to assess the quality of information, and subsequently verify information by cross-checking. Therefore, the hypothesis is as follows:

Hypothesis 9: The higher the level of secondary education, the more often journalists will verify online information, because higher educated journalists perceive online information as less credible.

\section{Method}

Data

The data were collected in 2010, using the membership email list of the Dutch Association of Journalists (NVJ). Between 60 to 70 percent of journalists is member of this professional association (Deuze, 2002). The Dutch Association for Journalists provided a database with 7281 email addresses of members, of which 5675 were valid (Hermans, Vergeer, \& Pleijter, 2011). Of all invitations that were sent out, 20\% resulted in completed questionnaires ( $N=1016)$, which is good for web questionnaires (Yetter \& Capaccioli, 2010). The questionnaire was a selfadministered web questionnaire on a large range of topics. The final sample after listwise deletion of respondent, due to partial non-response is 666 .

Measurements

Verification behavior and perceived online source credibility. Verification behavior of online information is the dependent variable in the proposed model, while perceived credibility from specific sources is the mediator variable. To measure verification behavior, we asked journalists "Can you indicate how you deal with information obtained from the Internet?" (see Table 1 listing the items; four point-scale: almost never-almost always). Perceived credibility was measured by asking journalists the following question: How credible do you generally consider information provided on websites of [list of organizations]?" (see Table 1 listing the organizations; four point-scale: extremely incredible - extremely credible). To reduce the number of indicators into a limited number of dimensions, as well as ensuring these dimensions of perceived credibility and verification behavior are distinct empirically, we performed a factor analysis (see Table 1). The criteria for the factor analysis we use are as follows: KMO > .50, eigen value $>1$, communality $>.20$, factor loading $>.30$, factor loading foreign factor $<.20$ ). The oblique rotated factor analysis showed that verification behavior of online information forms a distinct dimension (i.e. Factor 2). Furthermore, perceived credibility appears to be two-dimensional. The two distinct dimensions of perceived credibility are labeled (semi-)governmental credibility (factor 1) and commercial credibility (factor 3). The reliability (Cronbach's a) of the scales of (semi-) governmental and commercial perceived credibility are .796 and .799 
respectively. Cronbach's a for verification behavior is .719. For further analyses, summated scales were created, where a higher score indicated more credibility and more verification.

Table 1: Factor analysis on perceived credibility of information sources on the Internet and verification behavior

\begin{tabular}{|c|c|c|c|c|}
\hline & $\begin{array}{c}\text { Factor } 1 \\
\text { Credibility } \\
\text { (semi-) } \\
\text { Governmental } \\
\text { information }\end{array}$ & $\begin{array}{c}\text { Verification } \\
\text { information } \\
\text { behavior }\end{array}$ & $\begin{array}{c}\text { Factor } 3 \\
\text { Credibility } \\
\text { Commercial } \\
\text { Commercial } \\
\text { information }\end{array}$ & $\begin{array}{r}\text { Commu- } \\
\text { nality }\end{array}$ \\
\hline $\begin{array}{l}\text { International governmental organizations } \\
\text { nato }\end{array}$ & .881 & -.022 & -.071 & .723 \\
\hline Governmental organizations & .808 & -.008 & -.018 & .639 \\
\hline Political parties & .556 & .039 & .180 & .434 \\
\hline \multicolumn{5}{|l|}{ I always check information I retrieve } \\
\hline from the Internet through other sources & -.046 & .799 & .029 & .639 \\
\hline \multicolumn{5}{|l|}{ When I find information on the Internet, } \\
\hline I always try to find the original source & .061 & .637 & -.002 & .407 \\
\hline I always check information I receive via e-mail & -.023 & .601 & -.029 & .367 \\
\hline Interest groups & -.054 & .006 & .840 & .665 \\
\hline Industry organizations & -.036 & -.012 & .818 & .645 \\
\hline Companies & .182 & -.019 & .563 & .449 \\
\hline Eigenvalue & 3.082 & 1.903 & 1.253 & \\
\hline
\end{tabular}

Note: Factor loadings printed bold indicate the highest factor loadings for each of the three dimensions. 
Professional socialization. Journalism education was measured by asking journalists what their highest level of journalism education they successfully completed. Respondents could choose one of the following categories (in descending order): post-academic journalism program, master program journalism studies, school for journalism, internal training, otherwise, none), and subsequently recoded to (1) university master / post-doctoral program $(8.3 \%)$, (2) school of journalism (33.2\%) or (3) other such as courses provided by the employer $(58.6 \%)$. Secondary education was measured by asking for the highest successfully completed level (in descending order: university or post academic (33.6\%), university of applied sciences (47.6), primary or secondary school (18.8\%)). These two distinct measurements of education (i.e. journalism education and secondary education) correlate only moderately (Spearman's rho $=.176, \mathrm{p}<.05)$.

Age was measured by subtracting the year of birth of the respondent from the year of data collection (mean = $50.5, \mathrm{SD}=11.3$ ). The use of the Internet was measured by asking journalists how many hours a day they were active on the Internet (mean $=3.1, \mathrm{SD}=2.3$ ).

Work experience, indicator of informal socialization on the job, was measured by asking journalists in what year they started working as a journalist. Subtracting this number from the year of the data collection resulted in the number of years of professional experience (mean $=20.7, S D=11.6$ ).

Job activities and media types. Job activities were measured by providing journalists with an activity list and asking them to check all activities they performed on the job. This resulted in nine binary variables indicating whether a journalist performs a certain activity or not (see Table 2). Because journalists are increasingly performing multiple tasks in the process of news production, they could check multiple activities. Media type was measured by showing journalists a list of different media types and asking them whether they were working for these media types. These media types were collapsed into four general types: newspaper $(50.8 \%)$, magazines (47.9\%), broadcasting (28.7\%) and the Internet (17.4\%).

Table 2: Journalists' job activities

\begin{tabular}{lc} 
Activities & Percentage \\
\hline Writing texts & 83.3 \\
Editing texts & 56.0 \\
Desk research & 52.9 \\
Reporting & 47.6 \\
Managing and coordination & 37.7 \\
Photography & 33.9 \\
Web master & 25.2 \\
Presenting & 18.8 \\
Blogging & 9.2
\end{tabular}

$\mathrm{N}=666$; Activities sorted by percentages in decreasing order. Journalists can check multiple activities.

Time budget was measured by asking journalists how many hours they work in journalism on a weekly basis (mean $=38.3, \mathrm{SD}=13.4)$. Sex was measured by asking journalists whether they were male $(65.2 \%)$ or female $(34.8 \%)$. Analysis

To test our hypotheses, we use multiple regression analysis. We have three regression equations, one for the dependent variable verification behavior and two regression equations for the mediating variables of perceived 
credibility of (semi-)governmental websites and commercial websites. To test whether the mediation hypotheses are statistically significant, both effects (i.e. independent variable on mediator, and mediator on dependent variable) need to be statistically significant.

Because journalism education and secondary education are ordinal variables, the categories of these variables were included in the regression equations as dummy variables (Cohen, Cohen, West \& Aiken, 2002). Sex, the different types of media and the different job activities are binary measurements and, as such, can be entered into the regression equations. Essential checks on regression analysis assumptions (normality, linearity, and homoscedasticity) were performed. No violations of these technical assumptions were found. Furthermore, to assess whether independent variables are correlated too strong for regression analysis (i.e. multicollinearity), we calculated the Variance Inflation Factor (VIF) for each independent variable. However, no indications of multicollinearity were found: the highest value for the VIF is 4.323, well below the critical value of 10 .

\section{Findings}

Table 3 shows that most journalists check online information extensively: $36.8 \%$ of journalists claim they always check online information, while only .5\% of journalists claims never to verify online information. The median of the verification scale is relatively high (value $=8$ ): journalists always check online information in at least in two of three cases.

Table 3: Levels of verification of online information

\begin{tabular}{|c|c|c|c|c|}
\hline & & & & Cumulative \\
\hline & & & Percentage & Percentage \\
\hline 0 & Lowest & Never in all of the three presented cases & 0.5 & 0.5 \\
\hline 1 & & & 0.6 & 1.1 \\
\hline 2 & & & 0.9 & 2.0 \\
\hline 3 & & & 3.3 & 5.3 \\
\hline 4 & & & 4.1 & 9.3 \\
\hline 5 & & & 7.4 & 16.7 \\
\hline 6 & & & 13.2 & 29.9 \\
\hline 7 & & & 16.1 & 45.9 \\
\hline 8 & & & 17.3 & 63.2 \\
\hline 9 & Highest & Always in all of the three presented cases & $\underline{36.8}$ & 100.0 \\
\hline & & & 100.0 & 100.0 \\
\hline
\end{tabular}

$\mathrm{N}=666$, median $=8$ 
Table 4 shows the results of the regression analyses. Journalist having had higher journalism education do not verify online information more often than those with lower levels of journalism education $(b=.098, p>.050)$, and journalism education therefore does not explain any variance of verifying information $(\beta=.077, p>.05)$. Hypothesis 1 must be refuted. Work experience was expected to have a positive effect on how often journalists check online information. The findings show this is not the case: $\beta=-.012, p>.050$, as such refuting Hypothesis 2. Hypothesis 3 stated that there is an indirect effect of journalism education on verification behavior, mediated by perceived online credibility. Table 4 shows that journalism education does have a significant negative effect on perceived credibility of online information provided by (semi-)governmental websites: journalists with a higher level of journalism education perceive information from (semi-)governmental online sources as less credible $(b=-.210$, $p<.050)$. Journalism education is unrelated to perceived credibility of information from commercial online sources. However, both dimensions of perceived credibility show no significant effects on checking behavior $(\beta=-.013$, $p>.050$ and $\beta=-.012, p>.050$ ). These findings show there is no indirect effect of journalism education mediated through perceived information credibility - on online information verification. Therefore, we cannot confirm Hypothesis 3.

The findings show there is no significant effect of time spent on the Internet on perceived credibility of online information. Therefore, Hypothesis 4, suggesting an indirect effect of time spent on the Internet on verification behavior mediated by perceived credibility of online information, is refuted. There is, however, a direct effect of amount of time journalists spend on the Internet on how often journalists verify online information $(\beta=.107, p<$ .050): the more journalists spend time online, the more they verify online information.

Hypothesis 5 suggested that journalists working for traditional media, particularly newspapers and magazines, perceive online information as less credible and therefore will check online information more often. However, the findings show that working for any of these specific platforms has no significant effect on perceived credibility and verifying online information. Therefore, Hypothesis 6 is refuted.

As for specific activities journalists perform, most activities are unrelated to perceived credibility and verifying online information. There are, however, some exceptions. Journalists that perform photography check online information less than other journalists $(\beta=-.083, p<.50)$ while news reporters and managers check online information more often $(\beta=.140, p<.050$, resp. $\beta=.148, p<.050)$. Even though they check online information more often, they perceive online information as credible as other journalists. This finding does not support Hypothesis $6 a$. Web masters (as member of online staff) perceive online information from commercial sources as more credible $(\beta=$ $.082, p<.050)$, and subsequently check online these online commercial sources less often $(\beta=-.074, p<.050)$. This finding supports Hypothesis $6 \mathrm{~b}$. 
Table 4: Regression analysis explaining perceived web credibility and web info verification behavior

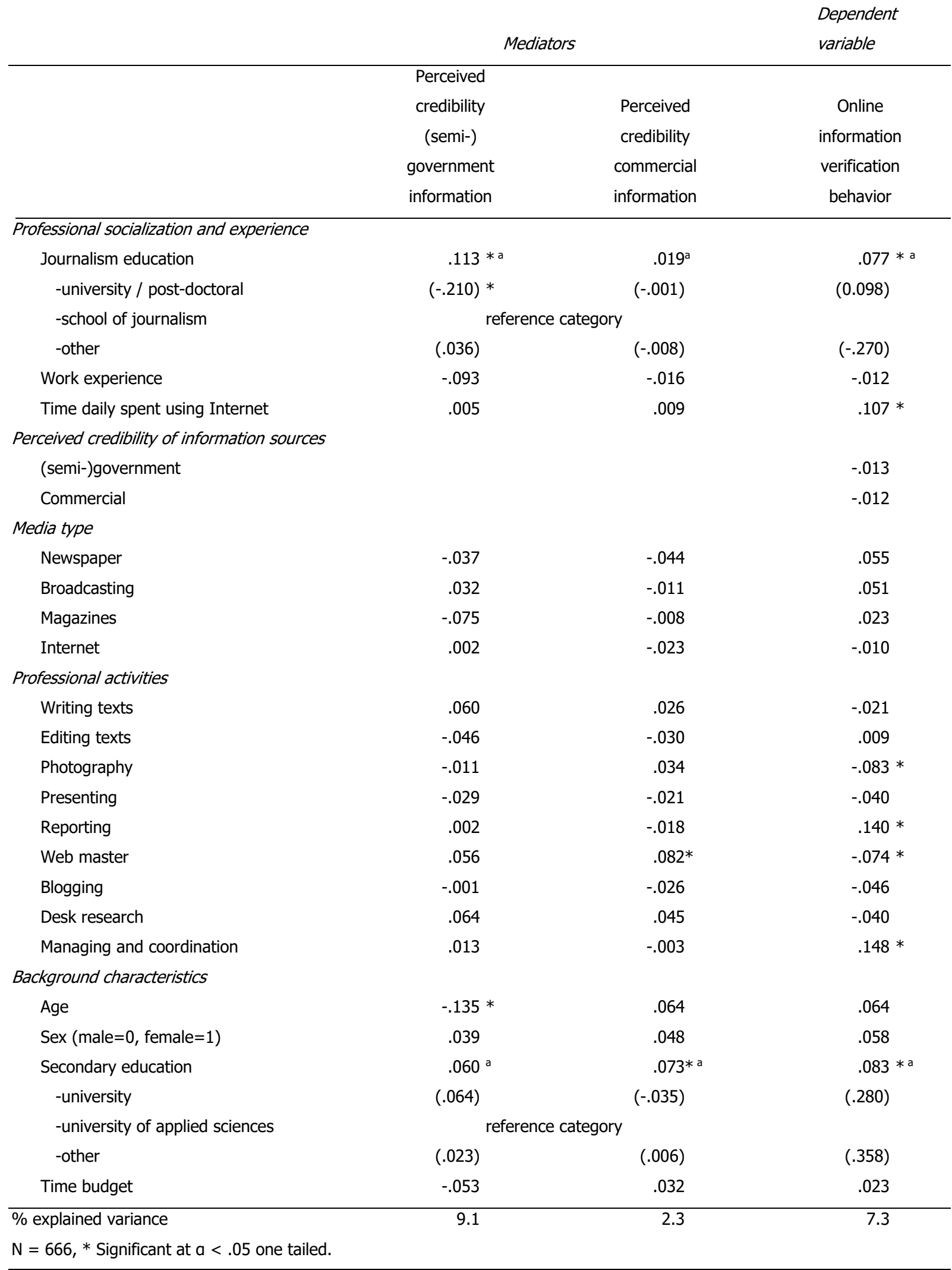

Note: Regression coefficients are standardized. Regression coefficients between brackets are unstandardized coefficients of dummy-variables. These are ordinal by comparing higher level categories to the next lower level categories. 
a Standardized regression coefficients of journalism education and secondary education are so-called Sheaf coefficients (Heise 1972), ranging from 0 to 1 . These coefficients indicate the relative strength of the association of these variables with the dependent variables, but not the direction of the association.

The findings show that, although spending more time online enables journalists to cross-check online information more often, Table 4 also shows that the total amount of time journalists work is unrelated to how often they check online information ( $\beta=.023, p>.050)$, and thus refuting Hypothesis 7.

Turning to the control variables, Table 4 shows that older journalists do not verify online information less often ( $\beta$ $=.064, \mathrm{p}>.050)$ as compared to younger journalists. This finding thus refutes Hypothesis 8 . However, older journalists do perceive online information from government as less credible $(\beta=-.135, p<.050)$. Apparently, this does not result in subsequent verification of online information.

Hypothesis 9 suggests an indirect effect of secondary education on verification behavior mediated by perceived credibility of online information. However, secondary education is unrelated to perceived credibility of (semi)governmental online information $(b=.064, p>.050)$. Still, even though the differences between levels of secondary education are not significant, secondary education in total is significantly related to perceived credibility of commercial online information ( $\beta=.073, p<.050)$. Secondary education also has a significant direct effect on checking behavior $(\beta=.083, p<.050$ ): higher educated journalists check information more frequently than those with lower education. However, because the direction of the effect of secondary education on perceived credibility is not conform the predictions and credibility has no effect on verification behavior, we refute Hypothesis 9 .

\section{Discussion}

This study set out to answer two questions. The first question focused on the role of perceive credibility: to what extent is perceived credibility of online information associated with verification behavior? The second question was to what extent is professional socialization associated with journalists' behavior of verifying the accuracy of online information? The findings show that overall, journalists in the Netherlands verify online information extensively: $36.8 \%$ of journalists claims to check online information always, while only $.5 \%$ claims never to verify online information. This suggests that most online information that is finds its way into news publications has been verified. This provides favorable conditions to produce news reports of high quality. To understand how higher and lower levels of online information verification can be explained, we formulated expectations in terms of professional socialization. However, the expectation that journalism education had taught journalists to approach online information with a critical attitude and not to believe online information as is, or to check information has been shown to be incorrect. The empirical findings show that journalism education has no direct or indirect effects mediated by perceived credibility - on verification of online information. There is however a negative effect of journalism education on perceived credibility of governmental websites, showing that higher educated journalists perceive online information of governmental sites as less credible. Secondary education has no significant effects on perceived credibility and verification behavior as predicted either. This means that more journalism education does, but secondary education does not contribute to perceiving online information as less credible and education in general does not lead (directly or indirectly) to more verification of online information. The conclusion is that journalists vary in the extent they check online information on its credibility, but it cannot be traced back to perceiving online information as less credible and to the level of education (journalism or secondary). These findings suggest that the perception of online information as being less credible is not the motive to verify the information. 
However, there are other correlates of perceived credibility and verification behavior. One interesting finding is that particularly managers in the newsroom appear to verify online information more often than others. Managers' role model position in the editorial office, might have them explicitly subscribe to professional journalistic behavior more strongly than other journalists. Reporters also verify online information more often than others do, while those that write and edit texts do not verify information more often. Furthermore, spending more time online has a positive effect on checking online information. These findings are in contrast with journalists that maintain the website as a web master and photographers: both groups of journalists verify online information less often. Webmaster facilitate online news production only in a technical sense, not in terms of content production. Photographers by nature of their work produce first hand visual accounts of events.

Older journalists are more skeptical about the credibility of (semi-)governmental information online, while for commercial online information age is unrelated. Although survey data do not allow us to separate age, period, and cohort effects simultaneously (Glenn, 2007), a possible interpretation might emerge for age as well as cohorts. The most plausible interpretation is that older generations of journalists were trained in the pre-Internet era and collecting and verifying information was quite different from today. They lack the experience and the skills that younger generations already learn at an early age in middle school. As a result, older journalists approach new technologies and new ways of collecting information and verifying them with skepticism.

\section{Conclusion}

Online information is here to stay whether, journalists perceive it as credible or not. Moreover, incorrect and false information will remain present on the Internet, even when Facebook and Google attempt to counter-attack the publication and dissemination of fake news on their platforms. This means that journalists and citizens need to remain critical about online information in general. Particularly young journalists that grew up as digital natives in the Internet age will use the Internet as an unquestionable and integral part of their daily activities in their professional and personal lives. Certainly, the use of online information has enormous benefits as compared to gathering information in the pre-Internet era, such as ease of access, the abundance of information and quick access. Still, caution on using online information is necessary. Particularly when algorithms increasingly govern the rapid spread of information online by sharing and liking information on news sites and social media. These algorithms however do not yet discriminate in truthful and false, or credible and incredible information, yet. Until computers can assist journalists in assessing the credibility of online information, journalists must continue to do this manually.

Having expected that professional socialization would have equipped journalists with the necessary critical views and skills to check online information, we were surprised to find hardly any empirical relations between journalists' journalism education, perception of online information credibility and verification behavior. These findings can be interpreted in a number of ways. First, primary and secondary education in the Netherlands and Internet experience is already at a high level. According to the OECD PISA ranking, education in the Netherlands ranks high as compared to other countries on reading, science and math (ranks 5, 4 and 10 respectively; OECD, 2012a, 2012b, 2012c). This suggests that journalism education may not able to contribute additionally in that respect. Also, the use of the Internet by the general Dutch population is among the highest in the world (i.e. over $90 \%$, fourth highest globally in 2011, Worldbank, 2016). This implies that, even before students enter journalism education, they already have 
ample Internet experience. This also suggests that in countries where levels of education are lower and Internet use is not as pervasive, education might contribute to increasing awareness about the quality of online information and how to assess information quality. A second interpretation is that, even though the level of education is high in the Netherlands, the marginal effects may also suggest that journalism education devotes too little attention in their educational program to best practices on how to verify online information accuracy. However, without an indepth analysis of educational journalism programs in the Netherlands, this is pure speculation. A further possible explanation is contextual, namely the economic malaise in the news media industry in the last decades: even though the general audience displays high interest in news, people often perceive news to be for free, especially the younger generations. Thus, traditional news organizations have difficulties to find profitable and sustainable business models to generate revenues. In the last decades, many newspaper publishers have had economic problems, are being taken over by foreign publishers, or have merged with other publishers. As a result, newsrooms have had to deal with cutbacks, resulting in smaller editorial staffs. This was expected to create more time pressure to produce the same news product with a smaller staff. Even though in our study a smaller time budget did not result is less verification, the time spent online has an effect: the more time journalists spend time online, the more they will check information. However, given the cutbacks, the reverse may be true as well: the less time journalists spend online, the less they will check online information. This suggests that when cutbacks are being made, journalists' working conditions in terms of access (time and equipment) to the Internet should not be decreased.

\section{Bibliographical references}

Breed, W. (1955). Social control in the newsroom: A functional analysis. Social Forces, 33(4), 326-335.

Cassidy. W.P. (2005). Variations on a theme: The professional role conceptions of print and online newspaper journalists. Journalism \& Mass Communication Quarterly, 82(2), 264-280.

Cassidy, W.P. (2007). Online news credibility: An examination of the perceptions of newspaper journalists. Journal of Computer-Mediated Communication, 12, 478-498.

Chan, J.M., Lee, F.L.F. and Pan, Z. (2006). Online news meets established journalism: How China's journalists evaluate the credibility of news websites. New Media \& Society, 8(6), 925-947.

Cohen, J., Cohen, P., West, S. G., \& Aiken, L. S. (2002). Applied Multiple Regression/Correlation Analysis for the Behavioral Sciences. Lawrence Erlbaum: Mahwah, NJ.

Davies, N. (2009). Flat Earth News. London: Vintage.

Deuze, M. (2002). Journalists in the Netherlands. An Analysis of the People, the Issues and the International Environment. Aksant, Amsterdam.

Deuze, M. and Dimoudi, C. (2002). Online journalists in the Netherlands. Towards a profile of a new profession. Journalism, 3, 85-100.

Flanagin, A.J. and Metzger, M.J. (2000). Perceptions of Internet information credibility. Journalism \& Mass Communication Quarterly, 773), 515-540.

Glenn, N.D. (2007). Age, period, and cohort affects. Retrieved from: http://www.sociologyencyclopedia.com/subscriber/uid=1008/tocnode?id=g9781405124331 yr2013 ch unk g97814051243317 ss1-22

Grabowicz, P. (2003). Weblogs bring journalists into a larger community. Nieman Reports, 57, 74-76.

Haas, T. (2006). Mainstream news media self-criticism: A proposal for future research. Critical Studies in Media Communication, 23, 350-355. 
Hargittai, E. and Hinnant, A. (2008). Digital inequality: Differences in young adults' use of the Internet. Communication Research, 35(5), 602-621.

Heise, D.R. (1972). Employing nominal variables, induced variables, and block variables in path analyses. Sociological Methods \& Research, 1(2), 147-173.

Hermans, L., Vergeer, M., and Pleijter, A. (2011). Nederlandse journalisten in 2010 [Dutch Journalists in 2010]. Nijmegen: Radboud Universiteit.

Hermida, A. (2012). Social journalism: Exploring how social media is shaping journalism. IN Siapera, E., and Veglis, A. (Eds.), The Handbook of Global Online Journalism, pp. 309-328, Wiley-Blackwell, Oxford. Retrieved from: http://onlinelibrary.wiley.com/doi/10.1002/9781118313978.ch17/summary

Johnson, T.J. and Kaye, B.K. (2000). Using Is believing: The influence of reliance on the credibility of online political information among politically interested Internet users. Journalism \& Mass Communication Quarterly, 77(4), 865-879.

Johnson, T.J. and Kaye, B.K. (2002). Webelievability: A path model examining how convenience and reliance predict online credibility. Journalism \& Mass Communication Quarterly, 79(3), 619-642.

Johnson, T.J. and Kaye, B.K. (2004). Wag the blog: How reliance on traditional media and the Internet influence credibility perceptions of weblogs among blog users. Journalism \& Mass Communication Quarterly, 81(3), 622-642.

Johnson, T.J. and Kaye, B.K. (2014). Credibility of social network sites for political information among politically interested Internet users. Journal of Computer-Mediated Communication, 19, 957-974

Johnson, T.J. and Kaye, B.K. (2015). Site effects how reliance on social media influences confidence in the government and news media. Social Science Computer Review, 33(2), 127-144.

Kirby, E. J. (2016, December 5). The city getting rich from fake news. BBC News. Retrieved from: http://www.bbc.com/news/magazine-38168281

Larsson, A.O. (2016). I shared the news today, oh boy. Journalism Studies, Q(0), 1-19.

Lasica, J.D. (2003). Blogs and journalism need each other. Nieman Reports, 57, 70-74.

Maksl, A., Craft, S., Ashley, S., \& Miller, D. (2016). The usefulness of a news media literacy measure in evaluating a news literacy curriculum. Journalism \& Mass Communication Educator, 1077695816651970. https://doi.org/10.1177/1077695816651970

OECD (2012a). International student assessment (PISA) - Science performance (PISA) - OECD Data. Retrieved from: https://data.oecd.org/pisa/science-performance-pisa.htm\#indicator-chart

OECD (2012b). International student assessment (PISA) - Mathematics performance (PISA) - OECD Data. Retrieved from: https://data.oecd.org/pisa/mathematics-performance-pisa.htm\#indicator-chart

OECD (2012c). International student assessment (PISA) - Reading performance (PISA) - OECD Data, available at: https://data.oecd.org/pisa/reading-performance-pisa.htm\#indicator-chart

Page, L., Brin, S., Motwani, R., and Winograd, T. (2001). The PageRank Citation Ranking: Bringing Order to the Web. Retrieved from http://ilpubs.stanford.edu:8090/422/

Pavlik, J. (2001). Journalism and New Media. Columbia University Press: New York.

Porlezza, C., and Russ-Mohl, S. (2012). Getting the facts straight in a digital era: Journalistic accuracy and trustworthiness. In C. Peters \& M. Broersma (Eds.), Rethinking Journalism (pp. 45-59). London: Routledge.

Reich, Z. (2011). Source credibility and journalism. Journalism Practice, 5(1), 51-67. 
Ruggiero, T.E. (2004). Paradigm repair and changing journalistic perceptions of the Internet as an objective news source. Convergence: The Journal of Research into New Technologies, 10, 92-104.

Singer, J.B. (2004). More than ink-stained wretches: The resocialization of print Journalists in converged newsrooms. Journalism \& Mass Communication Quarterly, 81(4), 838-856.

Tylor, J. (2015). An examination of how student journalists seek information and evaluate online sources during the newsgathering process. New Media \& Society, 178), 1277-1298.

Van Deursen, A. and Van Dijk, J. (2011). Internet skills and the digital divide. New Media \& Society, 13(6), 893911.

Vergeer, M. (2015). Peers and sources as social capital in the production of news online social networks as communities of journalists. Social Science Computer Review, 33(3), 277-297.

Weaver, D., Beam, R.A., Brownlee, B.J., Voakes, P.S. and Wilhoit, G. (2007). The American Journalist in the 21st Century: U.S. News People at the Dawn of a New Millennium. LEA, Mahwah: New Jersey.

Weischenberg, S., Malik, M., and Scholl, A. (2012). Journalism in Germany in the 21st century. In Weaver, D.H. and Willnat, L. (Eds.), The Global Journalist in the 21st Century), pp. 205-219. Routledge: New York.

Worldbank (2016). Internet users (per 100 people), availabe at: http://data.worldbank.org/indicator/IT.NET.USER.P2/countries/1W-NL?display=default

Yetter, G., and Capaccioli, K. (2010). Differences in responses to Web and paper surveys among school professionals. Behavior Research Methods, 42(1), 266-272. https://doi.org/10.3758/BRM.42.1.266

Yoon, Y. (2005). Examining journalists' perceptions and news coverage of stem cell and cloning organizations. Journalism \& Mass Communication Quarterly, 82(2), 281-300. 